\title{
Endometrial Clear Cell Adenocarcinoma
}

National Cancer Institute

\section{Source}

National Cancer Institute. Endometrial Clear Cell Adenocarcinoma. NCI Thesaurus. Code C8028.

A high-grade endometrial adenocarcinoma characterized by the presence of large neoplastic cells that display at least focal cytoplasmic clearing. The neoplastic cells form papillary, glandular, or sheet-like structures. 